\title{
Dimensionamento de um Reator UASB para Tratar o Vinhoto Gerado na Produção de Cachaça e Avaliação do Potencial Energético Advindo do Biogás e do Aproveitamento do Bagaço da Cana-de-Açúcar
}

\author{
Thaís M. M. Leitão, Yago S. Melgaço, Ana Paula L. Pimenta, \\ Emanuel M. F. Brandt \& Marcela R. Menezes
}

O estudo propôs o tratamento do vinhoto gerado durante a produção de cachaça artesanal por meio de um Reator Anaeróbio de Fluxo Ascendente e Manta de Lodo - UASB, visando à redução da carga orgânica presente nesse efluente aliada ao seu aproveitamento energético em conjunto com o bagaço da cana-de-açúcar. A degradação biológica anaeróbia do vinhoto, rico em matéria orgânica, produz biogás, o qual trás aos produtores uma opção energética renovável de ótimo rendimento por intermédio de sua queima, restando ainda o subproduto biofertilizante para a plantação de cana-de-açúcar. Os cálculos propostos para o dimensionamento do reator foram adaptados da teoria sugerida por Chernicharo (2007) para o tratamento de esgoto doméstico. Os resultados obtidos se encontraram dentro dos limites propostos, a eficiência de remoção de matéria orgânica seria satisfatória e a quantidade de biogás gerado seria alta, o que poderia resultar em economia para o produtor.Por fim, foi proposta a substituição da lenha, que fornece calor para a caldeira do alambique, pela queima do bagaço da cana como uma alternativa renovável de fornecer energia para a fabricação da cachaça. Com base nos valores de poder calorífico inferior dos possíveis combustíveis, foi encontrada a quantidade necessária de bagaço para suprir a mesma demanda energética e o resultado dos cálculos mostrou que essa substituição também seria viável.Nesse cenário, praticamente todo resíduo gerado na produção de cachaça seria transformado em recurso energético e deixado de ser descartado no ambiente, propiciando um desenvolvimento sustentável e contínuo.

Palavras Chave: Alambique; Tratamento Biológico; Aproveitamento Energético.

This study proposed the treatment of sugarcane vinasse, generated during the production of cachaça, through an Upflow Anaerobic Sludge Blanket-UASB, aiming at reducing the organic load present in this effluent combined with its energy use in conjunction with sugarcane bagasse. The anaerobic biological degradation of vinasse, rich in organic matter produces biogas, which brings back to the producers a renewable energy option for optimum performance through its burning, still leaving the by-product bio-fertilizer for planting sugarcane. The proposed calculations for the design of the reactor were adapted from the theory suggested by Chernicharo (2007) for the treatment of domestic sewage. The results obtained were within the proposed limits, the efficiency of removal of organic matter would be satisfactory and the amount of biogas generated would be high, which could result in savings for the producer. Finally, it was proposed to replace the wood for the sugarcane bagasse to provide heat to the boiler of the still as a renewable alternative to supply power to one of the manufacturing steps. Based on the values of lower calorific value of both possible fuels was found the required amount of firewood to meet the same energy demand and the result of the calculation shows that this substitution could be also feasible.In this case, virtually all waste generated in the production of cachaça would be transformed into an energy resource and no longer disposed of in the environment, providing a sustainable and continuous development.

Keywords: Sugarcane; UASB; Biological Treatment; Renewable Energy. 


\section{Introdução}

Diversos estudos apontam o envolvimento da gestão ambiental por meio de práticas que buscam amenizar a ação degradante do homem sobre o meio ambiente. Todo produto gerado nos processos fabris, não importa de que material seja feito, provoca um impacto no meio ambiente, seja em função de seu processo produtivo, das matérias primas que consome, ou devido ao seu uso ou disposição final. Com o surgimento de novas tecnologias, sistemas alternativos de produção têm implantado formas sustentáveis que proporcionam a integração de diferentes plantas de produção direcionando um subproduto gerado em um $27^{\circ}$ Congresso Nacional dos Estudantes de Engenharia Química - Goiânia - Goiás sistema em outro, servindo este de matéria prima reduzindo tanto os desperdícios quanto o descarte de subprodutos prejudiciais ao ambiente, além de maximizar os lucros (NIGRI et al., 2011).

Várias cadeias produtivas do agronegócio registram altas taxas de expansão e de geração de biomassa residual. A título de exemplo, o setor sucroalcooleiro é uma importante referência de como utilizar pelo menos uma grande parte dos resíduos resultantes das operações de produção. De acordo com a Associação Mineira dos Produtores de Cachaça de Qualidade (AMPAQ, 2015), o Brasil produz cerca de 1,5 bilhões de litros por ano de aguardente, sendo Minas Gerais o maior produtor de cachaça artesanal do país.

Uma preocupação corrente em relação à produção de cachaça é a destinação dos resíduos e efluentes de sua produção, dentre os quais se destacam o bagaço e o vinhoto que têm sido alvo de estudos por entidades ligadas à agricultura mineira, que buscam meios para aliar o aumento na qualidade do produto e melhor desempenho econômico dos alambiques, juntamente com a redução dos impactos que a atividade possa gerar ao meio ambiente (JÚNIOR et.al. 2009; MORAIS et. al., 2013).

Nesse contexto, o presente estudo consistiu em avaliar, descrever e propor perspectivas de integrações fabris para que o vinhoto e o bagaço gerados durante o processo da produção de cachaça artesanal sejam aproveitados de maneira eficiente. Para isso, foi proposto o tratamento do vinhoto por meio de um reator UASB. A degradação biológica anaeróbia do vinhoto, rico em matéria orgânica, produz uma mistura gasosa composta predominantemente de metano (CH4) e dióxido de carbono ( $\mathrm{CO} 2)$, chamada biogás, o qual trás aos produtores uma opção energética renovável de ótimo rendimento por intermédio de sua queima, restando ainda o subproduto biofertilizante para a plantação de cana-de- açúcar. Além disso, foi proposta a substituição da lenha como combustível que fornece calor para a caldeira do alambique, pela queima do bagaço da cana como uma alternativa renovável de fornecer energia para uma das etapas de fabricação da cachaça.

\section{Metodologia}

A partir de dados fornecidos pela produtora de cachaça artesanal, Destom Indústria e Comércio Ltda, localizada na zona rural de Faria Lemos (Minas Gerais) foi dimensionado um sistema para o tratamento do vinhoto gerado e proposta a substituição da lenha pelo bagaço de cana-de-açúcar.A destilaria tem capacidade para moer 16 toneladas por dia de cana-de-açúcar, produzir aproximadamente $1300 \mathrm{~L}$ de cachaça e gerar, como resíduo, aproximadamente $8000 \mathrm{~L}$ de vinhoto e 6 toneladas de bagaço.

Os cálculos propostos para o dimensionamento do sistema utilizando reator UASB foram adaptados da teoria de dimensionamento proposta por Chernicharo (2007), para os reatores anaeróbios aplicados ao tratamento de esgoto doméstico. Foram realizados cálculos para volume, altura e área do reator, tempo de detenção hidráulica, profundidade do compartimento de digestão, número de distribuidores, massa de microrganismos e carga biológica, eficiência de remoção de DBO e DQO, produção de lodo, produção de metano e, por fim, a quantidade de energia elétrica obtida a partir da conversão energética do biogás.

Para calcular a quantidade de bagaço necessária para substituir a quantidade de lenha que fornece calor para a caldeira do alambique foi necessário, primeiramente, obter valores de poder calorífico inferior (PCI) do bagaço 
e da lenha, em relação ao mesmo teor de umidade. Com base nos dados pesquisados na literatura e nos cálculos de conversão necessários, os valores de PCI adotados foram $3325 \mathrm{Kcal} / \mathrm{Kg}$ para a lenha e $1800 \mathrm{kcal} / \mathrm{kg}$ para o bagaço, ambos em relação a $50 \%$ de umidade.

\section{Resultados e Discussão}

Os resultados encontrados a partir dos cálculos para o dimensionamento do reator anaeróbio situaram-se dentro dos limites propostos de acordo com parâmetros apontados por Chernicharo (2007) para o dimensionamento de reatores para tratamento de esgoto doméstico. Inicialmente, considerou-se a carga orgânica volumétrica igual a $15 \mathrm{kgDQO} / \mathrm{m} 3$.dia, conforme a teoria e, com base nesse valor, os resultados encontrados para os cálculos de volume (V) e tempo de detenção hidráulica (TDH) foram iguais a 38,03 m3 e 4,75 horas, respectivamente. Esse tempo encontrado foi considerado baixo para o vinhoto, que é um afluente mais concentrado do que o esgoto doméstico, por isso, adotou-se 6,0 horas de detenção hidráulica. $\mathrm{O}$ valor encontrado para a altura do reator foi igual a 4,2 m e, no caso do tratamento de esgoto doméstico, em reatores que desenvolvem predominantemente o lodo tipo floculento, as velocidades ascensionais impostas ao sistema conduzem a reatores com alturas úteis entre 4,0 e $5,0 \mathrm{~m}$, portanto, o resultado encontra-se dentro dessa faixa. Tendo-se os valores do volume e da altura do reator, encontrou-se a área igual a 9,05 m2. A profundidade do compartimento de digestão foi considerada igual a 2,5 $\mathrm{m}$, pois de acordo com a teoria, esse deve ser o valor mínimo adotado. Quanto ao número de distribuidores, encontrou-se a quantidade de 4,53 então seriam adotados 5 para garantir melhor distribuição do afluente no reator. A massa de microorganismos encontrada foi $905,40 \mathrm{Kg}$ STV. A partir disso, encontrou-se a carga biológica de 0,63 $\mathrm{KgDQO} / \mathrm{KgSTV}$.dia, próximo da carga biológica esperada para esgoto doméstico, que varia entre 0,1 a $0,4 \mathrm{KgDQO} /$ KgSTV.dia. De acordo com os cálculos, o reator proposto apresentou uma eficiência de remoção satisfatória, equivalente a $63,68 \%$ para DQO e $71,42 \%$ para DBO. A produção de lodo diária encontrada equivale a 2,80 m3 e, o volume do compartimento de digestão seria igual a 22,64 m3, portanto seriam necessárias avaliações diárias para se estabelecer o momento de descarga do lodo. Já a produção de metano encontrada equivale a $92,39 \mathrm{~m} 3 /$ dia e, considerando-se um percentual de $75 \%$ de metano no biogás, a produção volumétrica de biogás seria de 123,19 m3/dia. A conversão energética de biogás em energia elétrica foi realizada através dos cálculos referentes ao Ciclo Otto, a partir do qual foi encontrado um valor igual a 236,59 kWh. Essa quantidade de energia elétrica foi considerada relativamente alta, o que poderia gerar economia para o produtor.

De acordo com os valores de PCI do bagaço e da lenha, notou-se que o PCI da lenha era 1,85 vezes maior do que o PCI do bagaço e, portanto, seria necessária uma massa de bagaço 1,85 vezes maior para suprir a mesma demanda energética, ou seja, seria necessário queimar $2590 \mathrm{~kg}$ de bagaço por dia para substituir a quantidade de lenha que, atualmente, fornece calor para a caldeira do alambique. Como são gerados aproximadamente $6000 \mathrm{~kg}$ de bagaço por dia durante a fabricação da cachaça artesanal, seria possível substituir toda a lenha gasta na caldeira pelo bagaço gerado no alambique e ainda sobraria um restante para dar continuidade à prática de alimentação do gado da fazenda onde o alambique está inserido.

\section{Conclusões}

Os resultados encontrados para o dimensionamento do reator UASB para tratamento do vinhoto se apresentaram dentro dos limites propostos, de acordo com parâmetros apontados por Chernicharo (2007) para o dimensionamento de reatores para tratamento de esgoto doméstico, feitas as considerações necessárias. A eficiência de remoção de carga orgânica encontrada, 63,68\% para DQO e $71,42 \%$ para DBO, foi satisfatória tendo em vista o grande potencial poluidor que o efluente apresenta, quando utilizado na fertirrigação, sem tratamento. Além disso, a geração de energia elétrica a partir da alta produção de biogás pelo reator trás aos produtores uma opção energética renovável 
de ótimo rendimento, que, além de proporcionar energia limpa, ajuda a custear os gastos em energia elétrica externa. De acordo com as especificidades encontradas para o reator anaeróbio, propõe-se o dimensionamento do separador trifásico, pois através dele ocorre a manutenção do lodo, conseguindo separar gás, sólido e líquido. Portanto, levando em conta os ganhos ambientais, o biodigestor é um excelente método de tratamento de resíduos, propiciando um desenvolvimento sustentável e contínuo, desde que o mesmo seja dimensionado de forma correta e eficiente.

A partir dos valores encontrados de poder calorífico inferior da lenha e do bagaço e nos cálculos realizados para convertê-los a um mesmo teor de umidade relacionado, foi possível encontrar a quantidade de bagaço necessária para substituir a quantidade de lenha responsável por gerar calor para a caldeira do alambique em estudo. $\mathrm{O}$ valor encontrado foi altamente viável, pois apontou que toda a quantidade de lenha consumida atualmente na caldeira pode ser substituída pelo bagaço gerado durante o processo de fabricação da cachaça artesanal.

Finalmente, para realizar as propostas de utilização mais sustentável dos resíduos gerados durante a fabricação da cachaça artesanal, recomenda-se uma avaliação da viabilidade econômica de implantação de uma estrutura de produção integrada.

\section{Referências Bibliográficas}

1. AMPAQ - Associação Mineira dos Produtores de Cachaça de Qualidade. Disponível em: <http://www.ampaq.com. br/?op=conteudo\&id=124>. Acesso em out. 2015.

2. Chernicharo, C. A. de L. Princípios do tratamento biológico de águasresiduárias: reatores anaeróbios. 2. ed. Belo Horizonte: Departamento de Engenharia Sanitária e Ambiental, 2007.

3. Júnior, B. C.; Libânio, J.C; Galinkin, M.; Oliveira, M.M. Embrapa - Agroenergia da biomassa residual: perspectivas energéticas, socioeconômicas e ambientais. 2. ed. Foz do Iguaçu: FAO. 2009.

4. Morais, M. P. De; Oliveira, J. M. S. R.; Souza, M. F. De; Silva, A. R. Diagnóstico ambiental da produção de aguardente em uma cooperativa dos produtores de cachaça de alambique na região calcária do centro-oeste de Minas Gerais. UNIFOR- MG, Formiga, v. 8, n. 1, p. 103-118, jan./jun. 2013.
5. Nigri, E. M; Leite, W. O.; Faria, P.E. De; Filho, E.R. Produção integrada: aplicação de novas tecnologias e formas de gestão para diminuição de custos e impactos ambientais no processo de produção de cachaça. $6^{\circ}$ Congresso Brasileiro de Engenharia de Fabricação, 11 a 15 de abril de 2011 - Caxias do Sul - RS - Brasil.

\section{Thaís M. M. Leitão*, Yago S. Melgaço, Ana Paula L. Pimenta, Emanuel M. F. Brandt \& Marcela R. Menezes}

Pontifícia Universidade Católica De Minas Gerais Belo Horizonte, MG, Brasil.

*E-mail: thaismm1191@gmail.com 